\title{
4-Hydroxychalcone Attenuates Hyperaldosteronism, Inflammation, and Renal Injury in Cryptochrome-Null Mice
}

\author{
Qi Qu, ${ }^{1}$ Bingguang Dai, ${ }^{1}$ Bo Yang, ${ }^{1}$ Xuelian Li, ${ }^{1}$ Yimin Liu, ${ }^{2}$ and Fuling Zhang ${ }^{1}$ \\ ${ }^{1}$ Department of Cardiovascular Surgery, The Fourth People's Hospital of Jinan City, Jinan 250031, China \\ ${ }^{2}$ Department of Cardiovascular Surgery, Qilu Children's Hospital of Shandong University, Jinan 250031, China \\ Correspondence should be addressed to Yimin Liu; yiminliujinan@126.com and Fuling Zhang; zhangfulingjinan@126.com
}

Received 7 May 2014; Accepted 16 May 2014; Published 9 June 2014

Academic Editor: Chuncho Han

Copyright ( 2014 Qi Qu et al. This is an open access article distributed under the Creative Commons Attribution License, which permits unrestricted use, distribution, and reproduction in any medium, provided the original work is properly cited.

\begin{abstract}
In the present study, we aimed to investigate the preventive effects of 4-hydroxychalcone $(4 \mathrm{HCH})$ on resistant hypertension. We used cryptochrome-null mice, which characteristically show high plasma aldosterone levels, inflammation, and renal injury. The cryptochrome-null mice received high-salt treatment and were treated orally with $4 \mathrm{HCH} 10 \mathrm{mg} / \mathrm{kg}, 4 \mathrm{HCH} 20 \mathrm{mg} / \mathrm{kg}$, and $4 \mathrm{HCH} 40 \mathrm{mg} / \mathrm{kg}$, respectively. The salt administration in cryptochrome-null mice is able to induce an increase in systolic pressure which is associated with hyperaldosteronism, inflammation, and kidney injury. Treatment with $40 \mathrm{mg} / \mathrm{kg} 4 \mathrm{HCH}$ reduced systolic hypertension, serum IL-1 $\beta$, and TNF- $\alpha$ levels and suppressed the activation of nuclear factor kappa-light-chain-enhancer of activated B cells $(\mathrm{NF}-\kappa \mathrm{B})$ and renal injury. The impact of $4 \mathrm{HCH}$ on the hyperaldosteronism, inflammation, and kidney injury provides new insights for future development of therapeutic strategies in resistant hypertension.
\end{abstract}

\section{Introduction}

Resistant hypertension (RH) refers broadly to high blood pressure that is resistant to pharmacologic therapy. Although the etiology of resistant hypertension is almost always multifactorial, aldosterone excess has been shown to contribute importantly to the development of $\mathrm{RH}$ [1]. There is evidence that aldosterone can promote endothelial dysfunction and induce vascular inflammation, vascular and myocardial fibrosis, and myocardial ischemia [2-4]. Consistent with the high degree of aldosterone excess demonstrable in patients with resistant hypertension, blockade of aldosterone has been demonstrated to provide particular benefit to $\mathrm{RH}$ [5].

Chalcones (1,3-diaryl-2-propen-1-ones) belong to the largest class of plant secondary metabolites and are considered to be precursors of flavonoids and isoflavonoids serving in plant defense mechanisms to counteract reactive oxygen species in order to survive and prevent molecular damage and damage by microorganisms, insects, and animals [6].
Chalcones and their derivatives exerted a lot of biological properties $[7,8]$, but few previous reports referred to the ability of these classes of compounds to lower blood pressure via the blockade of aldosterone. 4-Hydroxychalcone $(4 \mathrm{HCH})$ is an alpha, beta-unsaturated ketone with the core structure of chalcone and one hydroxyl substituent on the 4 positions of the A ring. We present for the first time the evidence that $4 \mathrm{HCH}$ inhibits $\mathrm{RH}$ by attenuating hyperaldosteronism, inflammation, and renal injury in cryptochrome-null mice (CNM).

Cryptochrome-null mice show increased mRNA expression and protein levels of $3 \beta$ hydroxysteroid dehydrogenase [9]. The enzyme is expressed particularly in the zona glomerulosa, where aldosterone production is known to exclusively take place. In the present study, we used cryptochrome-null mice, which characteristically show high plasma aldosterone levels, to evaluate the efficacy of $4 \mathrm{HCH}$ to lower blood pressure and prevent progressive hyperaldosteronism, inflammation, and renal injury. 


\section{Materials and Methods}

2.1. Drugs. $4 \mathrm{HCH}$ with $98 \%$ purification was obtained following the extraction and separation using a column chromatographic method [10].

2.2. Animals. This study was performed in accordance with the Guide for the Care and Use of Laboratory Animals. Care was taken to minimize discomfort, distress, and pain to the animals. The CNM were developed by the way introduced by Vitaterna et al. [11]. CNM received high-salt treatment. The normal salt chow had a $0.2 \% \mathrm{NaCl}$ content, whereas the highsalt chow had a $3.15 \% \mathrm{NaCl}$ content, and the drinking water contained $1 \% \mathrm{NaCl}$ and $0.2 \% \mathrm{KCl}$.

2.3. Experimental Design. Forty-eight of these mice were allocated equally into 4 groups: CNM group, CNM and $4 \mathrm{HCH}-10$ group, $\mathrm{CNM}$ and $4 \mathrm{HCH}-20$ group, and $\mathrm{CNM}$ and $4 \mathrm{HCH}-40$ group. The other 12 wild-type (WT) littermates mice were used as the control group receiving normal salt treatment. From then on, the 5 groups of mice were orally administered saline, $10 \mathrm{mg} / \mathrm{kg} 4 \mathrm{HCH}, 20 \mathrm{mg} / \mathrm{kg} 4 \mathrm{HCH}$, $40 \mathrm{mg} / \mathrm{kg} 4 \mathrm{HCH}$, and saline, respectively. $4 \mathrm{HCH}$ was dissolved in distilled water and administrated orally twice daily using a feeding needle for 35 days, and control group received double distilled water instead of $4 \mathrm{HCH}$.

2.4. Blood Pressure Measurement. Blood pressure was determined in conscious, trained mice using a noninvasive computer-automated tail-cuff system (BP-98A, Softron, Shanghai, China). The average value of 12 measurements was used for data analysis.

2.5. Blood Biochemical Analysis. After 32 weeks of treatment, blood was obtained for biochemical analysis by cardiac puncture before the mice were killed. Serum IL- $1 \beta$, TNF- $\alpha$, and aldosterone were measured using a commercially available enzyme immunoassay kit (Shanghai Jinma Biological Technology, Inc., China) according to the protocol described by the manufacturer.

2.6. Quantification of $N F-\kappa B$ Activity. At the end of the 32-week experimental period, kidney tissue samples were collected. Activated NF- $\kappa \mathrm{B}$ was quantified in kidney tissue extracts via ELISA technique using the PathScan PhosphoNF $\kappa$ B p65 (Ser536) Sandwich ELISA Antibody Pair (Shanghai Yubo Biological Technology, Inc., China), following the manufacture's instruction. The protein expression levels of $\mathrm{NF}-\kappa \mathrm{B}$ were measured by Western blot analysis.

2.7. Histological Examination of Kidney Sections. Kidney samples were fixed in $4 \%$ buffered formalin ( $\mathrm{pH} 7.2$ ), processed, and embedded in paraffin wax. Sections of $5 \mathrm{~mm}$ thickness were then generated and stained with Periodic acid-Schiff reagent for subsequent light microscope examination. Histological evaluation was performed in a blinded manner. A minimum of two slides per rat were read.
2.8. Statistical Analysis. The data were expressed as mean \pm SEM and results were analyzed by ANOVA followed by Dunnett's $t$ test. $P<0.05$ was considered significant.

\section{Results}

3.1. The Effect of $4 \mathrm{HCH}$ on Blood Pressure of Mice. CNM have elevated blood pressure compared with their WT littermate controls (Figure 1$)$. WT mice $(n=12)$ exhibited a systolic pressure of $103.1 \pm 5.5$. In contrast, CNM $(n=10)$ were hypertensive $(118.0 \pm 8.6)$. At 10 and $20 \mathrm{mg} / \mathrm{kg}, 4 \mathrm{HCH}$ did not produce a significant change from blood pressure baseline. At the higher dosage of $40 \mathrm{mg} / \mathrm{kg}, 4 \mathrm{HCH}$ lowered blood pressure in CNM $(P<0.05)$ (Figure 1$)$.

3.2. The Effect of $4 \mathrm{HCH}$ on Serum Aldosterone Levels. Figure 2 shows plasma aldosterone concentrations in CNM and WT mice, respectively. Serum aldosterone levels were significantly greater in CNM compared with WT mice $(P<0.001)$. However, aldosterone levels in the $40 \mathrm{mg} / \mathrm{kg} 4 \mathrm{HCH}$ and $20 \mathrm{mg} / \mathrm{kg} 4 \mathrm{HCH}$ groups were significantly lower than those in the CNM group $(P<0.01$ and $P<0.05$, resp.).

3.3. The Effect of $4 H C H$ on Serum $I L-1 \beta$ and TNF- $\alpha$ Level. In comparison to CNM group (Figure 3), treatment with 10 and $20 \mathrm{mg} / \mathrm{kg} 4 \mathrm{HCH}$ resulted in a marked decrease in IL$1 \beta$ levels compared with those in CNM group $(P<0.05$ and $P<0.01$, resp.). In addition, the levels of TNF- $\alpha$ were significantly increased in CNM group (Figure 4). $4 \mathrm{HCH}$ $(40 \mathrm{mg} / \mathrm{kg})$ suppressed CNM-induced TNF- $\alpha$ production $(P<0.05)$.

3.4. The Effect of $4 \mathrm{HCH}$ on Protein Expression of $N F-\kappa B$. The protein expression of NF- $\kappa \mathrm{B}$ represents NF- $\kappa \mathrm{B}$ activation. As shown in Figure 5(a), protein expression of NF- $\kappa$ B was significantly increased in the CNM group, suggesting CNM induced a predominant increase in nuclear translocation of NF- $\kappa \mathrm{B}$ substantially. Conversely, level of $\mathrm{NF}-\kappa \mathrm{B}$ protein decreased in the nucleus of kidney cells of $4 \mathrm{HCH}(40 \mathrm{mg} / \mathrm{kg})$ group (Figure 5(b)).

3.5. The Effect of $4 \mathrm{HCH}$ on Renal Injury. On histologic analysis, CNM with high-salt treatment developed severe glomerulosclerosis and tubulointerstitial injury and moderate tubulointerstitial infiltration with inflammatory cells (Figure 6(b)). It was dramatically reduced and became more normal in $4 \mathrm{HCH}(40 \mathrm{mg} / \mathrm{kg})$ treated mice (Figure 6(c)). Figure 6(a) showed that there were no marked renal abnormalities in WT mice.

\section{Discussion}

In the present study, we demonstrated that $4 \mathrm{HCH}$ reduces hypertension in CNM mice. This antihypertensive property of $4 \mathrm{HCH}$ may be explained by the attenuation of hyperaldosteronism and anti-inflammatory activities and recovery of renal injury. 


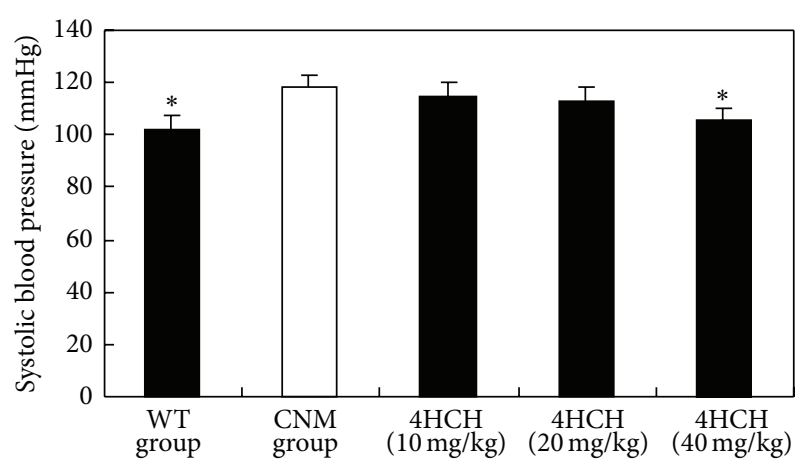

Figure 1: Effect of $4 \mathrm{HCH}$ on systolic blood pressure. Data are presented as the SEM. ${ }^{*} P<0.05$ as compared with CNM group.

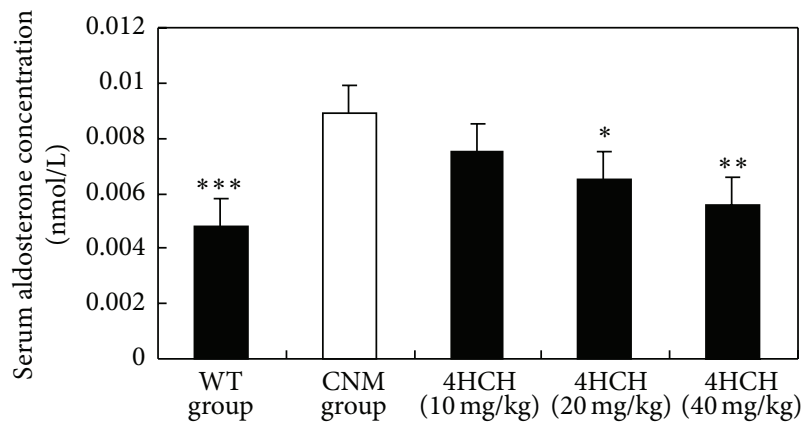

FIGURE 2: Effect of $4 \mathrm{HCH}$ on serum aldosterone levels. Data are presented as the SEM. ${ }^{*} P<0.05$ as compared with CNM group, ${ }^{* *} P<0.01$ as compared with CNM group, and ${ }^{* * *} P<0.001$ as compared with CNM group.

A now very sizable body of literature implicates aldosterone as an important mediator of incident hypertension and severity of hypertension, and, in particular, a common cause of resistance to antihypertensive treatment [12-14]. CNM show an adrenal disorder characterized by chronic overproduction of aldosterone that persists even in the reduced plasma renin activity [9]. The levels of aldosterone measured in the current study relate well to previously published studies [11]. The studies suggest that hypertension in highsalt-treated CNM was caused by mineralocorticoid receptor activation owing to both hyperaldosteronism and high-salt exposure. Here we have clearly demonstrated $4 \mathrm{HCH}$ lower level of aldosterone and blood pressure. It indicated that blockade of the aldosterone pathway by $4 \mathrm{HCH}$ prevented the increase in systolic pressure (Figure 1).

The importance of inflammation as being central to the development of atherosclerosis has been a fundamental tenet of cardiovascular medicine [15-17]. The low-grade inflammation occurs in the vasculature in various conditions that predispose to cardiovascular disease, including hypertension [18]. We noted that the CNM in the present study developed inflammation following high-salt treatment and in the absence of elevated blood pressure. It is consistent with previous findings that renal proinflammatory response plays an important role in mediating hypertension [19-22]. In our study, we show in CNM that salt-sensitive hypertension

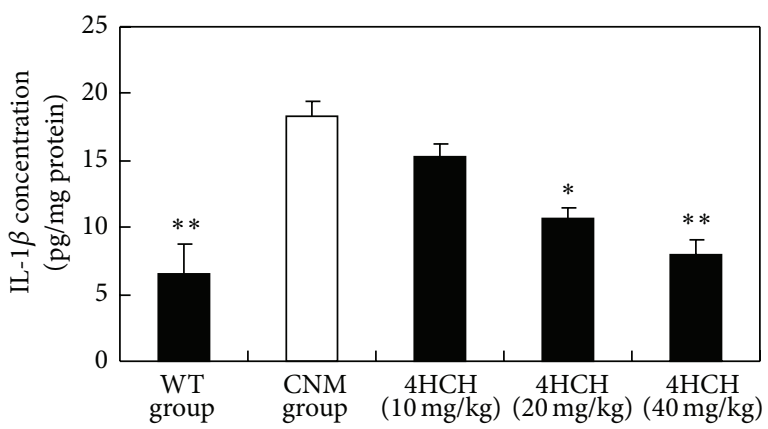

FIGURE 3: Effect of $4 \mathrm{HCH}$ on IL- $1 \beta$ level. Values represent the mean \pm SEM. ${ }^{*} P<0.05$ versus CNM group. ${ }^{* *} P<0.01$ versus $\mathrm{CNM}$ group.

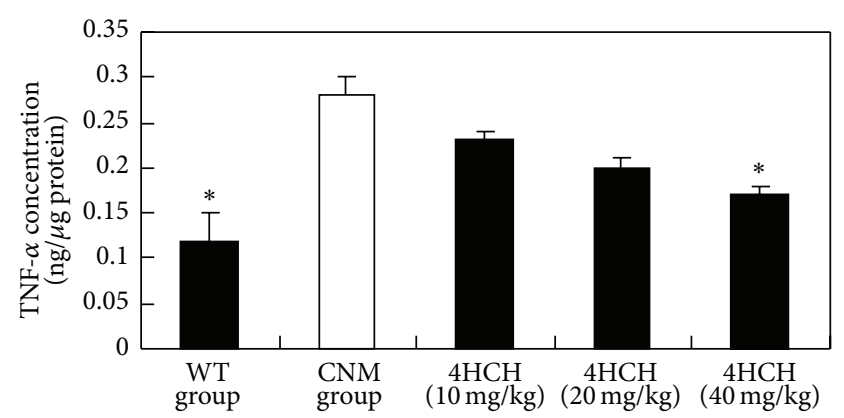

FIGURE 4: Effect of $4 \mathrm{HCH}$ on TNF- $\alpha$ level. Values represent the mean \pm SEM. ${ }^{*} P<0.05$ versus $\mathrm{CNM}$ group.

increased serum IL-1 $\beta$ and TNF- $\alpha$ level, which are normalized by $4 \mathrm{HCH}$ treatment.

$\mathrm{NF}-\kappa \mathrm{B}$ is a key transcription factor in the activation of genes related to proinflammatory response. It is one of the important renal mechanisms linking proinflammatory response to SS hypertension [23]. The present study demonstrates that a high-salt-induced renal activation of NF- $\kappa \mathrm{B}$ correlates with a significant upregulation of IL- $1 \beta$ and TNF$\alpha$ level in CNM. Our results indicate that $32 \mathrm{wk}$ of treatment with $4 \mathrm{HCH}$ suppressed high-salt-induced renal activation of NF- $\kappa$ B (Figure 6). Such a mechanism contributes probably to the beneficial effect of $4 \mathrm{HCH}$ on hypertension in CNM.

It is known that salt-sensitive hypertension in human and experimental animal model has been associated with progressive kidney damage leading to end-stage renal disease caused by elevated inflammation [24, 25]. Consequently, in the present study, we hypothesized that the $4 \mathrm{HCH}$ ameliorates hypertension and the associated kidney injury. The renal protection is evident from histopathologic observations including markedly reduced tubular cast formation and fibrosis in the kidney (Figure 6). This is the first study to demonstrate that $4 \mathrm{HCH}$ has a direct effect on protection against salt-induced kidney injury dependent on its ability to lower blood pressure.

In conclusion, this study demonstrates that salt administration in CNM is able to induce an increase in systolic pressure which is associated with hyperaldosteronism, inflammation, and kidney injury. These arterial modifications 


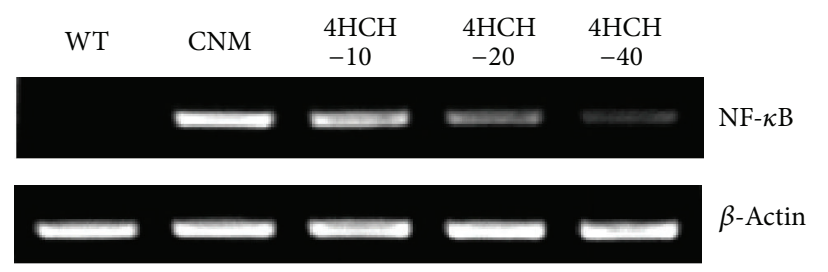

(a)

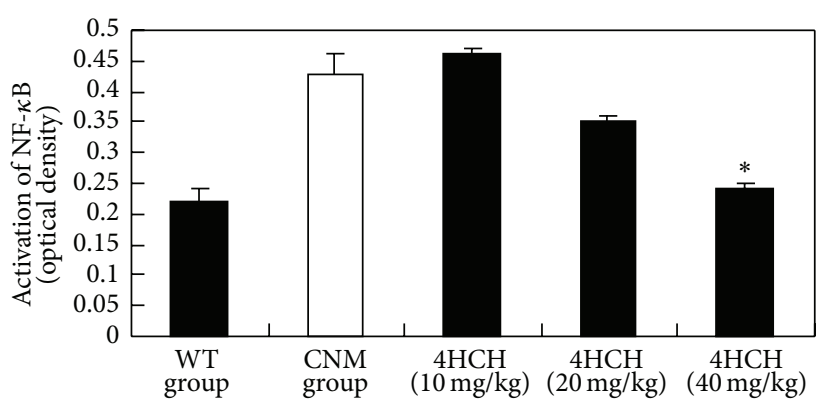

(b)

Figure 5: Effect of $4 \mathrm{HCH}$ on protein expression of NF- $\kappa$ B. Values represent the mean \pm SEM. ${ }^{*} P<0.05$ versus CNM group.

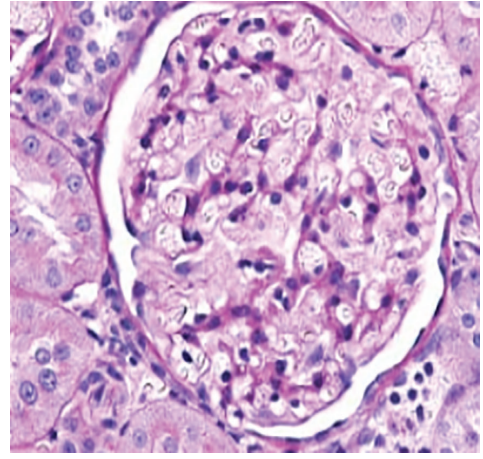

(a)

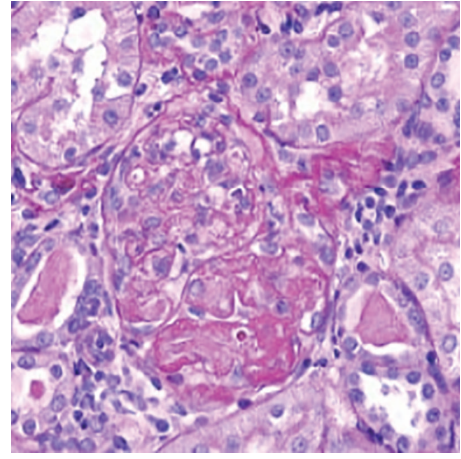

(b)

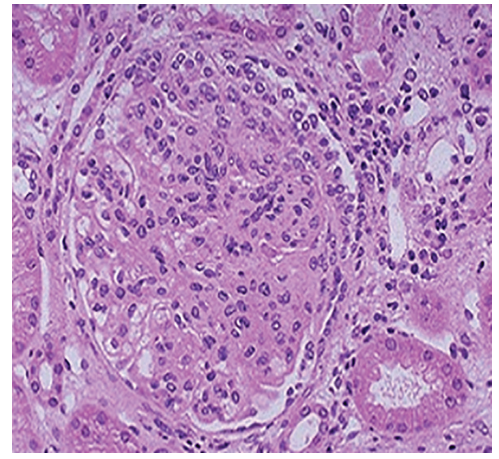

(c)

FIGURE 6: Effects of $4 \mathrm{HCH}$ on salt-induced kidney damage were evaluated by morphological analysis of (a) WT mice, (b) CNM, and (c) $4 \mathrm{HCH}-40$ mice. Magnification $\times 200$.

could represent an early step in the development of resistant hypertension. These changes were all reversed by orally administrated $4 \mathrm{HCH}$. The impact of $4 \mathrm{HCH}$ on the hyperaldosteronism, inflammation, and kidney injury provides new insights for future development of therapeutic strategies in resistant hypertension.

\section{Conflict of Interests}

The authors declare that there is no conflict of interests regarding the publication of this paper.

\section{References}

[1] D. A. Calhoun, D. Jones, S. Textor et al., "Resistant hypertension: siagnosis, evaluation, and treatment a scientific statement from the american heart association professional education committee of the council for high blood pressure research," Hypertension, vol. 51, no. 6, pp. 1403-1419, 2008.

[2] J. N. Cohn and W. Colucci, "Cardiovascular effects of aldosterone and post-acute myocardial infarction pathophysiology," American Journal of Cardiology, vol. 97, no. 10, pp. 4-12, 2006.

[3] J. W. Funder, “The nongenomic actions of aldosterone," Endocrine Reviews, vol. 26, no. 3, pp. 313-321, 2005.

[4] E. L. Schiffrin, "Effects of aldosterone on the vasculature," Hypertension, vol. 47, no. 3, pp. 312-318, 2006.
[5] N. Chapman, J. Dobson, S. Wilson et al., "Effect of spironolactone on blood pressure in subjects with resistant hypertension," Hypertension, vol. 49, no. 4, pp. 839-845, 2007.

[6] S. Hirai, Y.-I. Kim, T. Goto et al., "Inhibitory effect of naringenin chalcone on inflammatory changes in the interaction between adipocytes and macrophages," Life Sciences, vol. 81, no. 16, pp. 1272-1279, 2007.

[7] N. J. Lawrence, R. P. Patterson, L.-L. Ooi, D. Cook, and S. Ducki, "Effects of $\alpha$-substitutions on structure and biological activity of anticancer chalcones," Bioorganic and Medicinal Chemistry Letters, vol. 16, no. 22, pp. 5844-5848, 2006.

[8] Y. Kimura, M. Taniguchi, and K. Baba, "Antitumor and antimetastatic activities of 4-hydroxyderricin isolated from Angelica keiskei roots," Planta Medica, vol. 70, no. 3, pp. 211219, 2004.

[9] M. Doi, Y. Takahashi, R. Komatsu et al., "Salt-sensitive hypertension in circadian clock-deficient Cry-null mice involves dysregulated adrenal Hsd3b6," Nature Medicine, vol. 16, no. 1, pp. 67-74, 2010.

[10] H. Ni, X.-H. Zhou, H.-H. Li, and W.-F. Huang, "Column chromatographic extraction and preparation of cordycepin from Cordyceps militaris waster medium," Journal of Chromatography B, vol. 877, no. 22, pp. 2135-2141, 2009.

[11] M. H. Vitaterna, C. P. Selby, T. Todo et al., "Differential regulation of mammalian period genes and circadian rhythmicity by cryptochromes 1 and 2," Proceedings of the National Academy of Sciences of the United States of America, vol. 96, no. 21, pp. 1211412119, 1999. 
[12] M. Alajmi, A. T. Mulgrew, J. Fox et al., "Impact of continuous positive airway pressure therapy on blood pressure inpatientswithobstructive sleepapneahypopnea: ameta-analysis of randomizedcontrolled trials," Lung, vol. 185, pp. 67-72, 2007.

[13] L. Mo and Q. He, "Effect of long-term continuous positive airway pressure ventilation on blood pressure in patients with obstructive sleep apnea hypopnea syndrome: a meta-analysis of clinical trials," Zhonghua Yi Xue Za Zhi, vol. 87, no. 17, pp. 11771180, 2007.

[14] P. Haentjens, A. Van Meerhaeghe, A. Moscariello et al., "The impact of continuous positive airway pressure on blood pressure in patients with obstructive sleep apnea syndrome: evidence from a meta-analysis of placebo-controlled randomized trials," Archives of Internal Medicine, vol. 167, no. 8, pp. 757-765, 2007.

[15] F. Kim, M. Pham, I. Luttrell et al., "Toll-like receptor-4 mediates vascular inflammation and insulin resistance in diet-induced obesity," Circulation Research, vol. 100, no. 11, pp. 1589-1596, 2007.

[16] P. J. Boyle, "Diabetes mellitus and macrovascular disease: mechanisms and mediators," American Journal of Medicine, vol. 120, no. 9, pp. S12-S17, 2007.

[17] J. Nigro, N. Osman, A. M. Dart, and P. J. Little, "Insulin resistance and atherosclerosis," Endocrine Reviews, vol. 27, no. 3, pp. 242-259, 2006.

[18] S. A. Cooper, A. Whaley-Connell, J. Habibi et al., "Reninangiotensin-aldosterone system and oxidative stress in cardiovascular insulin resistance," American Journal of Physiology, vol. 293, no. 4, pp. H2009-H2023, 2007.

[19] B. Rodríguez-Iturbe, J. Herrera-Acosta, and R. J. Johnson, "Interstitial inflammation, sodium retention, and the pathogenesis of nephrotic edema: a unifying hypothesis," Kidney International, vol. 62, no. 4, pp. 1379-1384, 2002.

[20] B. Rodríguez-Iturbe, H. Pons, Y. Quiroz et al., "Mycophenolate mofetil prevents salt-sensitive hypertension resulting from angiotensin II exposure," Kidney International, vol. 59, no. 6, pp. 2222-2232, 2001.

[21] K. Shen, F. A. DeLano, B. W. Zweifach, and G. W. SchmidSchonbein, "Circulating leukocyte counts, activation, and degranulation in Dahl hypertensive rats," Circulation Research, vol. 76, no. 2, pp. 276-283, 1995.

[22] A.-K. Siegel, P. Kossmehl, M. Planert et al., "Genetic linkage of albuminuria and renal injury in Dahl salt-sensitive rats on a high-salt diet: comparison with spontaneously hypertensive rats," Physiological Genomics, vol. 18, pp. 218-225, 2004.

[23] V. Alvarez, Y. Quiroz, M. Nava, H. Pons, and B. RodríguezIturbe, "Overload proteinuria is followed by salt-sensitive hypertension caused by renal infiltration of immune cells," American Journal of Physiology, vol. 283, no. 5, pp. F1132-F1141, 2002.

[24] N. Tian, K. D. Thrasher, P. D. Gundy, M. D. Hughson, and R. D. Manning Jr., "Antioxidant treatment prevents renal damage and dysfunction and reduces arterial pressure in salt-sensitive hypertension," Hypertension, vol. 45, no. 5, pp. 934-939, 2005.

[25] N. Tian, J.-W. Gu, S. Jordan, R. A. Rose, M. D. Hughson, and R. D. Manning Jr., "Immune suppression prevents renal damage and dysfunction and reduces arterial pressure in salt-sensitive hypertension," American Journal of Physiology, vol. 292, no. 2, pp. H1018-H1025, 2007. 


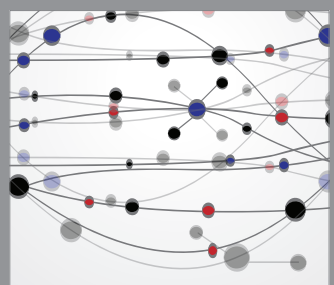

The Scientific World Journal
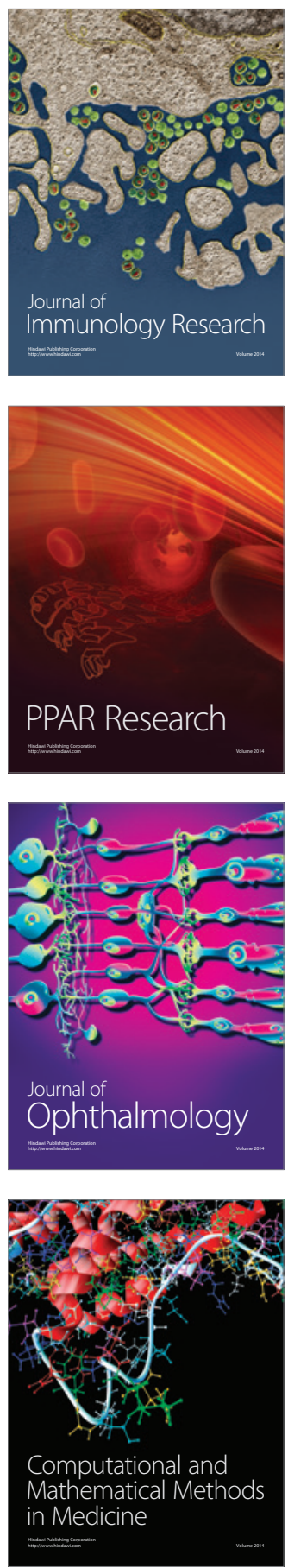

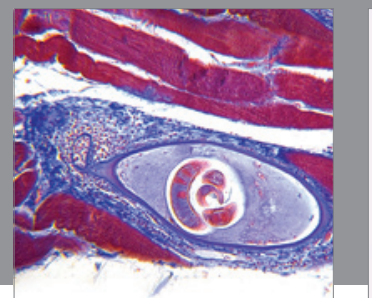

Gastroenterology

Research and Practice
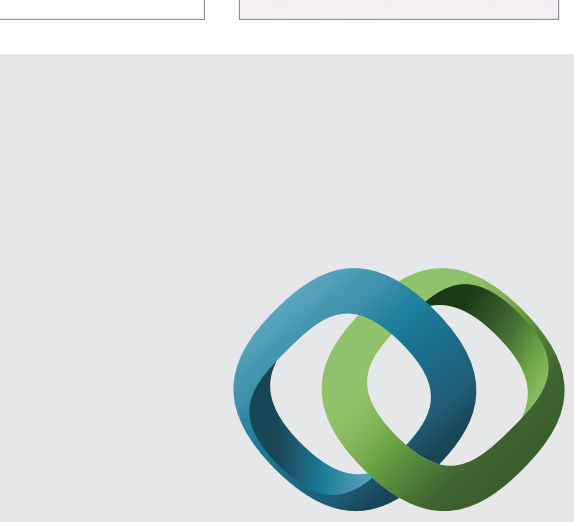

\section{Hindawi}

Submit your manuscripts at

http://www.hindawi.com
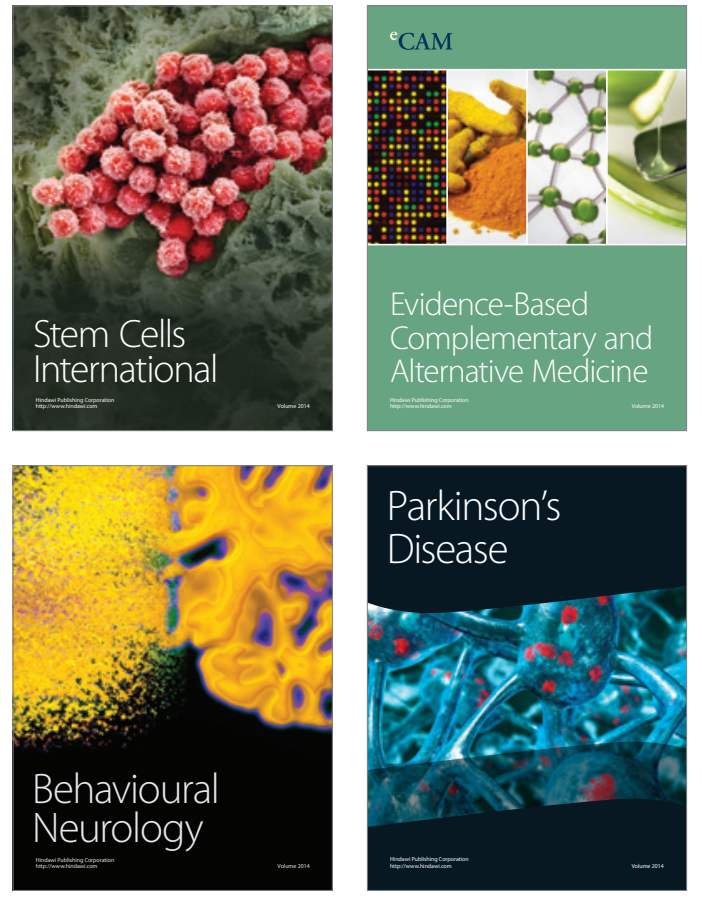
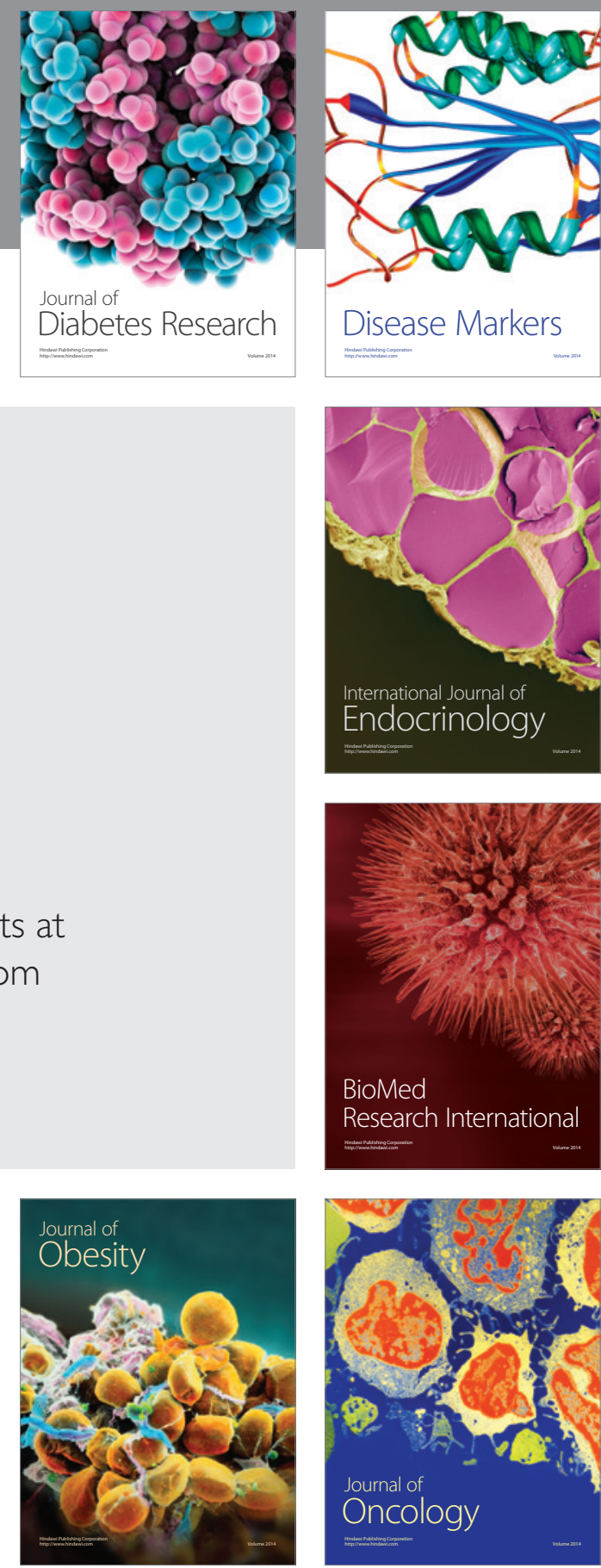

Disease Markers
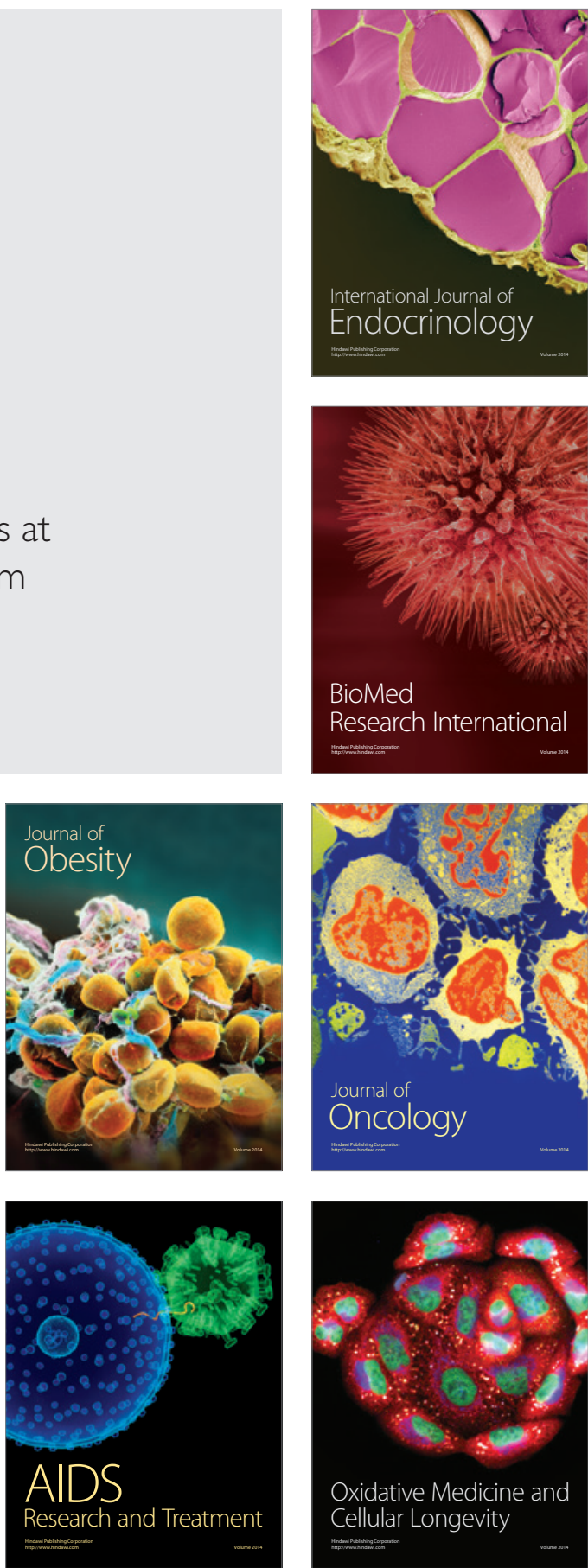